\title{
The management of type 2 diabetes before, during and after Covid-19 infection: what is the evidence?
}

Leszek Czupryniak ${ }^{1 *}$, Dror Dicker ${ }^{2,3+}$, Roger Lehmann ${ }^{4+}$, Martin Prázný ${ }^{5 \dagger}$ and Guntram Schernthaner ${ }^{6,7^{*}}$ (])

\begin{abstract}
Patients with Covid-19 place new challenges on the management of type 2 diabetes, including the questions of whether glucose-lowering therapy should be adjusted during infection and how to manage a return to normal care after resolution of Covid-19 symptoms. Due to the sudden onset of the pandemic, physicians have by necessity made such important clinical decisions in the absence of robust evidence or consistent guidelines. The risk to patients is compounded by the prevalence of cardiovascular disease in this population, which alongside diabetes is a major risk factor for severe disease and mortality in Covid-19. We convened as experts from the Central and Eastern European region to consider what advice we can provide in the setting of type 2 diabetes and Covid-19, considering the evidence before, during and after infection. We review recommendations that have been published to date, and consider the best available - but currently limited_evidence from large observational studies and the DARE-19 randomized control trial. Notably, we find a lack of guidance on restarting patients on optimal antidiabetic therapy after recovering from Covid-19, and suggest that this may provide an opportunity to optimize treatment and counter clinical inertia that predates the pandemic. Furthermore, we emphasize that optimization applies not only to glycaemic control, but other factors such as cardiorenal protection. While we look forward to the emergence of new evidence that we hope will address these gaps, in the interim we provide a perspective, based on our collective clinical experience, on how best to manage glucose-lowering therapy as patients with Covid-19 recover from their disease and return to normal care.
\end{abstract}

Keywords: Covid-19, Type 2 diabetes, Glucose-lowering therapy

\section{Introduction}

Physicians are adapting to a new era in healthcare brought about by the Covid-19 pandemic.[1] Among the myriad of challenges faced is the management of patients for whom Covid-19 risk is elevated, especially given the

*Correspondence: leszek.czupryniak@wum.edu.pl; guntram@schernthaner. eu

†Dror Dicker, Roger Lehmann, and Martin Prázný Contributed equally

${ }^{1}$ Department of Diabetology and Internal Medicine, Medical University of Warsaw, Warsaw, Poland

${ }^{6}$ Department of Medicine I, Rudolfstiftung Hospital Vienna, 1030 Vienna, Austria

Full list of author information is available at the end of the article epidemiological evidence that diabetes and cardiovascular disease are major risk factors for severe Covid-19 and mortality.[2]-[13].

As experts in diabetology from the Central and Eastern European region, we convened to consider what advice we can provide for clinicians managing patients with type 2 diabetes, including the large proportion of patients who also present with cardiovascular disease or high cardiovascular risk. We note that several recommendations are already published, albeit with some contradictions;[14] [21] however, we do not feel there are sufficient data available for us to adjudicate between these recommendations or to make our own evidence-based recommendations. original author(s) and the source, provide a link to the Creative Commons licence, and indicate if changes were made. The images or other third party material in this article are included in the article's Creative Commons licence, unless indicated otherwise in a credit line to the material. If material is not included in the article's Creative Commons licence and your intended use is not permitted by statutory regulation or exceeds the permitted use, you will need to obtain permission directly from the copyright holder. To view a copy of this licence, visit http://creativecommons.org/licenses/by/4.0/. The Creative Commons Public Domain Dedication waiver (http://creativeco mmons.org/publicdomain/zero/1.0/) applies to the data made available in this article, unless otherwise stated in a credit line to the data. 
Furthermore, we are concerned about the lack of guidance on restarting patients on optimal antidiabetic therapy post-Covid-19, and the potential impact of clinical inertia with regards to optimizing glucose-lowering therapy.[22].

As the pandemic progresses, we expect more evidence to emerge that may help to inform diabetes management in a Covid-19 setting. A first step comes from a realworld report on Covid-19 mortality among patients with type 2 diabetes in the UK. This nationwide study suggested that the pandemic does not provide grounds to change overall glucose-lowering drug preferences.[23].

In this article, we summarize what is and what is not known about managing type 2 diabetes during the Covid19 pandemic, discuss recommendations made to date, review the implications of the latest real-world evidence, and make our own suggestions for patients who are returning to normal care after recovery from Covid-19.

\section{Why does diabetes care need updating for the Covid-19 era?}

In patients with diabetes, the rates of severe disease and mortality during Covid-19 infection are elevated compared with non-diabetic individuals.[2]-[12, 23] Several pathological mechanisms have been proposed to underlie this phenomenon, and have been detailed extensively elsewhere [24]-[31]. Hyperglycemia is also associated with mortality [32, 33], raising the possibility that longterm optimal glucose control in the general diabetes population may be of particular importance for reducing mortality risk for those patients who later contract Covid-19.

Epidemiological studies have identified factors other than hyperglycaemia that heighten risk among patients with diabetes who are infected with Covid-19; unsurprisingly, these include advanced age and systemic inflammation as well as comorbidities such as obesity, hypertension, coronary artery disease, chronic kidney disease, and a history of stroke or heart failure $[1,6,10$, 33]-[49]. The widespread prevalence of these comorbidities, and proposed pathological overlap between their pro-inflammatory and pro-coagulative states and Covid-19, has added new complexity to diabetes care $[10,24,25,35,40,50]-[56]$, as has the observation that in some patients inflammation may be ongoing after the resolution of acute Covid-19 [57]. Similarly, even after discharge, the risk of mortality or new onset major adverse cardiovascular events (MACE) may remain high [10]. Elderly patients with type 2 diabetes may be a particular concern, owing to the position of advanced age as the most significant risk factor for poor outcomes with Covid-19.
The challenge of managing diabetes $[1,58]$ and its comorbidities [59] while under pandemic (and, at times, lockdown) conditions adds to the burden placed upon physicians. Of particular concern, there may be more restricted access to new initiation of glucose-lowering drugs; [60] meanwhile, patients' control of diabetes may worsen [61]. Covid-19 itself has been linked to fluctuating and elevated glucose levels that can be indicative of poor prognosis, and can be difficult to manage upon hospitalization [33, 47, 48, 62]-[65].

Inadequate glycaemic control can be a risk factor for the development of diabetic ketoacidosis (DKA), [66][68] which is typically seen in patients who are volumedepleted as a result of fever and inadequate fluid intake, [66] symptoms that can occur in Covid-19. By contrast, little is known about hypoglycaemia in patients with Covid-19; in non-Covid-19 settings, hypoglycaemia can be a significant risk factor for poor outcomes in intensive care [69].

In the case of the glucagon-like peptide-1 receptor agonist (GLP-1 RA) and sodium-glucose transporter 2 inhibitor (SGLT2i) classes, patients may miss out on the important cardiorenal benefits that these agents offer $[22,60]$-attributes that may even warrant exploration for the treatment mild or moderate Covid-19. Access to cardiology services themselves may also be impeded. In the first wave of the pandemic, several studies reported reductions in acute cardiovascular hospitalizations that suggested delayed care, such as primary percutaneous coronary intervention (PCI) procedures in patients with diabetes and ST-segment elevation myocardial infarction (STEMI) [70]-[73]. Even after admission, testing for Covid-19 status can delay necessary treatment [74]. An international study also found a stark reduction in diagnostic procedures [75]. Collectively, estimates have suggested that the impact on cardiology services will lead to a large number of excess deaths as an indirect consequence of Covid-19.[76] It is hoped that access has subsequently improved, but some issues may still remain and could re-emerge in the event of new waves of large-scale hospitalizations.

Beyond diabetes and its immediate comorbidities, the overall physical and mental health of patients with diabetes can also decline due to the socioeconomic impacts of Covid-19, such as lockdown, economic hardship and bereavement; indeed, anxiety has increased in patients with diabetes [1]. Thus, some patients with type 2 diabetes are particularly vulnerable during the pandemic.

\section{What evidence and recommendations are available for glycaemic control in a Covid-19 setting?}

Following a literature search, we have reviewed various recommendations [14] $-[21]$ and reviews [77, 78] now 


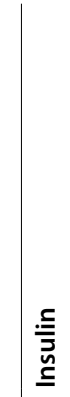

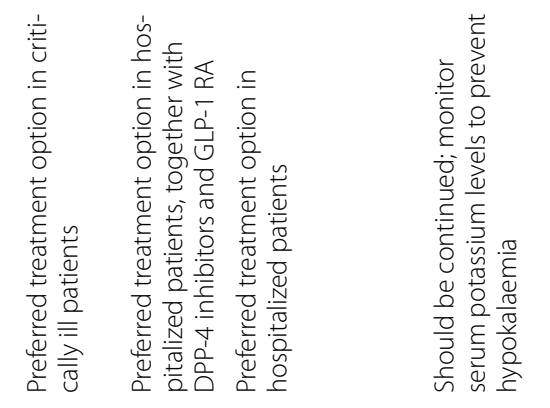

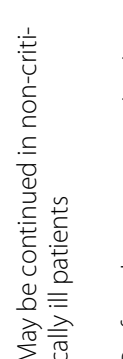

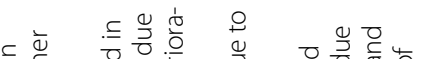

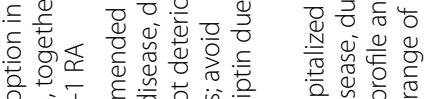

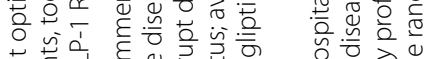

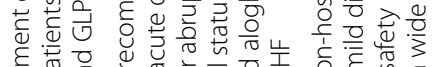

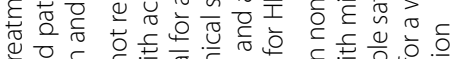

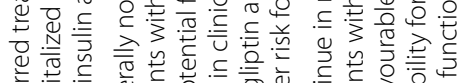

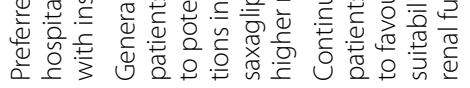

งे

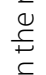

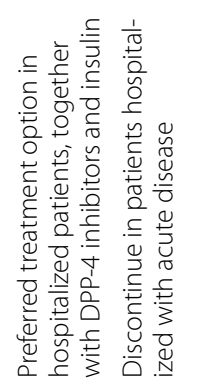

咛产

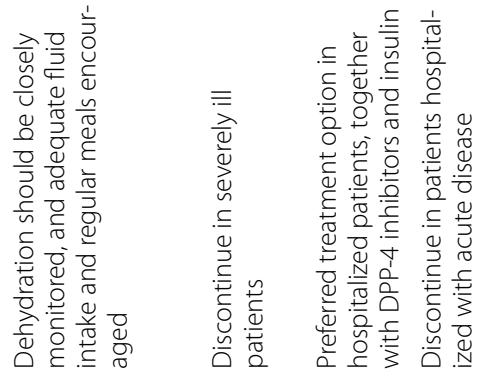

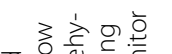

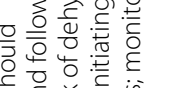

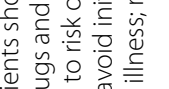

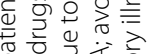

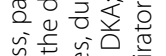

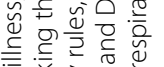

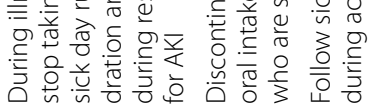

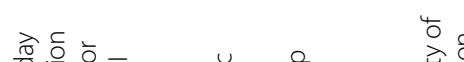

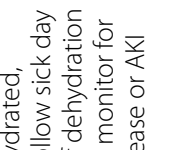

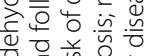

은 흔 응

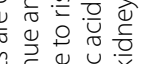

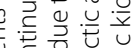

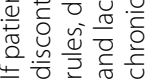

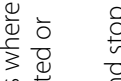

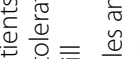

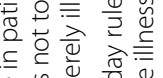

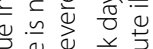

总矛

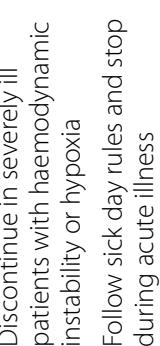

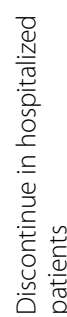

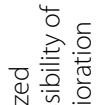

충

促

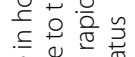

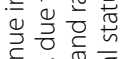

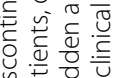

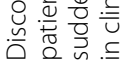

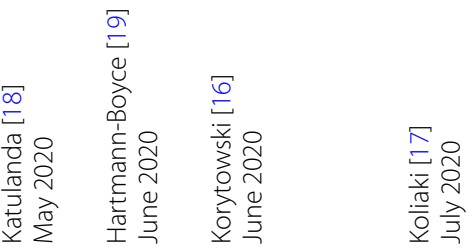

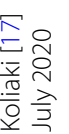

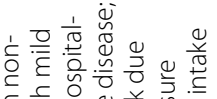

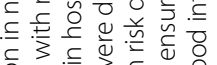

은

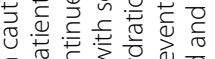

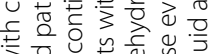

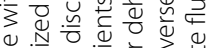

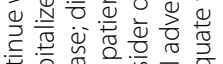

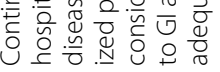

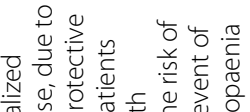

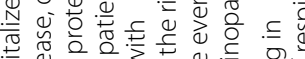

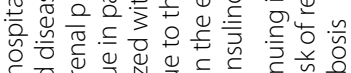

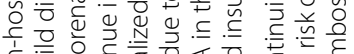

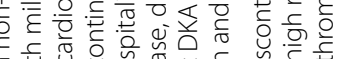

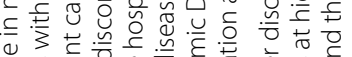

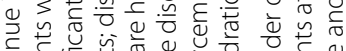

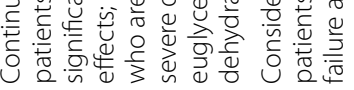

을

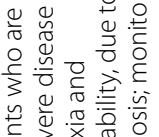

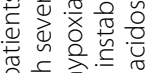

은.

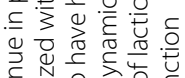

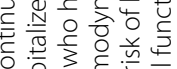

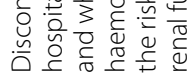

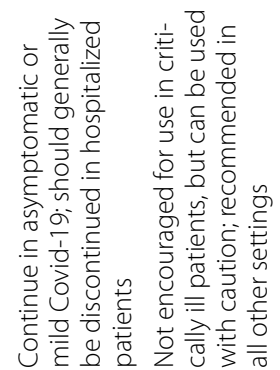

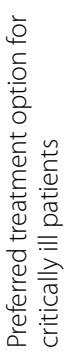

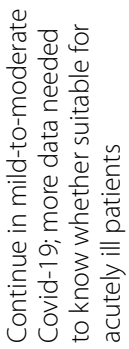

흉ㅎㅎ

$\frac{0}{8} \frac{0}{0}$

is

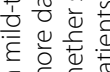

$\subseteq \varepsilon \frac{1}{3} \stackrel{0}{0}$

엉

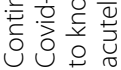

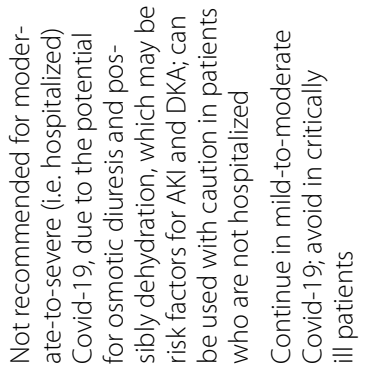

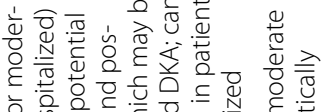

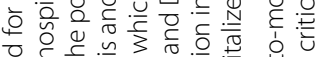



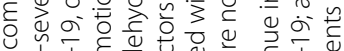

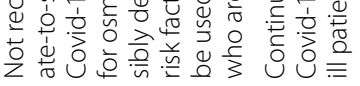

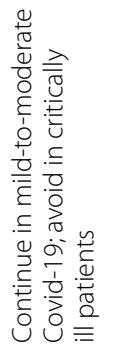

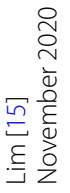

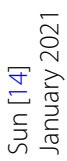


available on managing diabetes in a Covid-19 setting (Table 1). While we applaud the efforts to rapidly disseminate advice in the fast-evolving circumstances of a novel virus pandemic, the challenge for physicians is that the guidance in some aspects lacks consistency (Fig. 1a) [14]-[21]. This is largely because of the many data gaps that mean we still cannot say definitively whether each glucose-lowering drug class has a negative, positive or neutral effect on Covid-19 outcomes. In particular, we find that there is minimal guidance on how to restart glucose-lowering therapies after temporary cessation due to Covid-19 [14]-[21, 77, 78].

There is also only limited, if any, guidance on how to de-intensify insulin regimens after discharge in patients initiated with insulin during hospitalization [14]-[21, 77, 78] - a scenario that has become more common due to the frequent need for insulin in patients hospitalized with Covid-19. For these patients, we can apply our existing knowledge from discharging patients in non-Covid-19 settings, as the principles are similar; the challenge is only to ensure that expertise on best practice is shared with the greater number of clinicians who may now be managing patients in such a scenario.

Overall, evidence is conflicting as to which glucoselowering drugs are associated with the most favourable outcomes in patients with Covid-19 (Fig. 1b) and for the most part relies on observational data rather than randomized controlled trials. Large mortality studies have suggested either a benefit or no significant difference with metformin [23, 79]-[87] and SGLT2i; [39, 65]-[88] a benefit or neutral effect or even a negative effect with dipeptidyl peptidase-4 inhibitors (DPP-4i); $[23,89]-[101]$ a benefit or neutral effect with GLP-1 RA; [23, 88, 95] and a negative effect with insulin (Table 2) [23, 63, 102]-[104]. However, these observations may well be largely explained by confounders, and it is still not clear whether any of glucose-lowering agents provide true protection from Covid-19 [23, $88,105]$. Despite our reservations, the data do provide some reassurance on the lack of a safety signal, even for

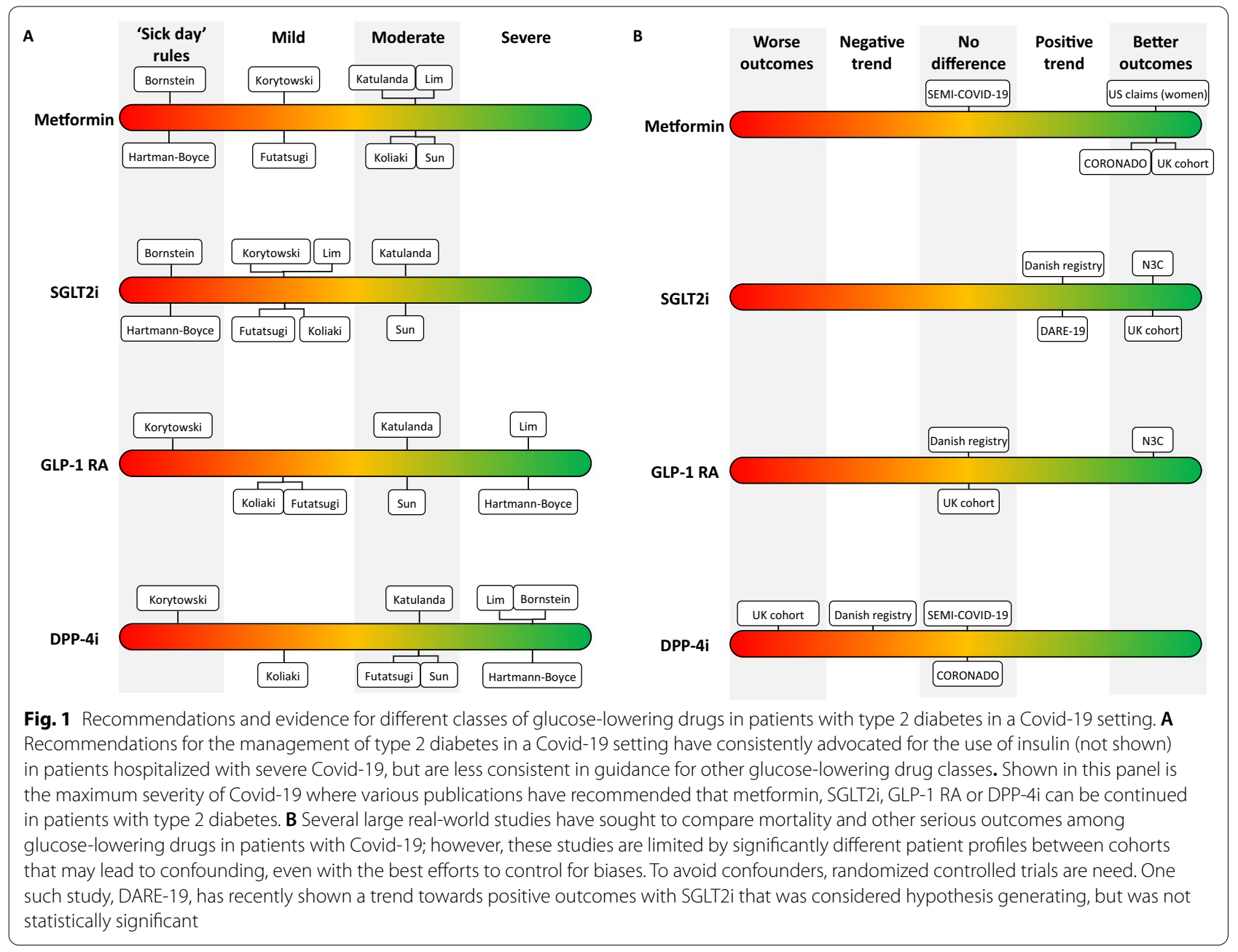




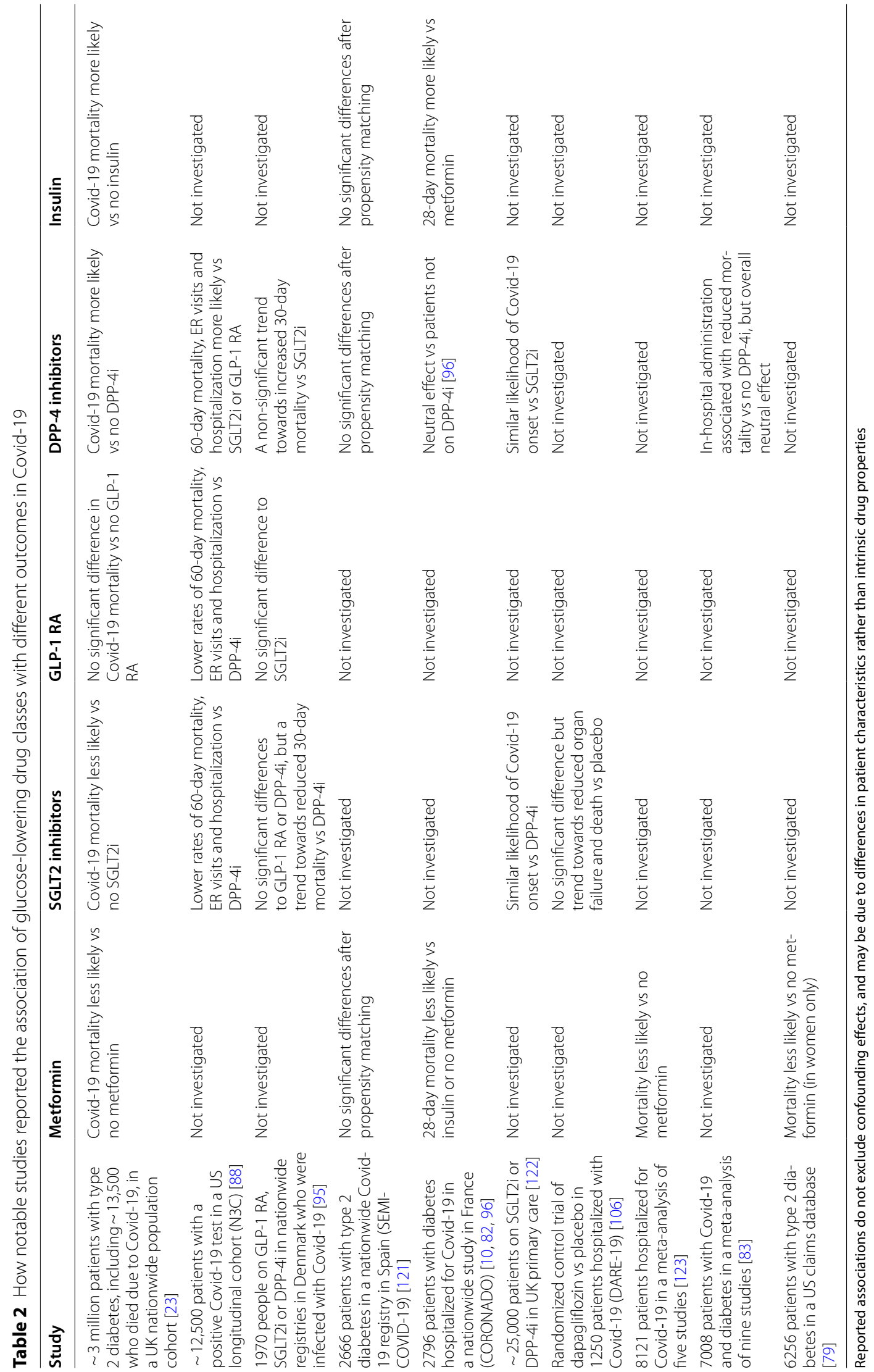


insulin where confounding factors were considered the likely explanation for the apparent negative effect [23].

For SGLT2i, a recent randomized controlled trial provided further reassurance on safety. In the DARE19 study, 1,250 patients hospitalized with Covid-19 at 95 sites in the US, Brazil, Mexico, Argentina, India, Canada and the UK, and who had cardiometabolic risk factors for developing serious complications, were randomized to receive dapagliflozin (an SGLT2i) or placebo between April 2020 and January 2021 [106]. Around half the patients had type 2 diabetes, and none had type 1 diabetes [106]. After 30 days, $11 \%$ of patients assigned to dapagliflozin and $14 \%$ of patients assigned to placebo had either died or suffered organ failure, most commonly respiratory or cardiovascular decompensation; looking at mortality only, the rates were $7 \%$ with dapagliflozin and 9\% with placebo [106]. Although there was no statistically significant improvement in these outcomes, as had been hoped for, the investigators noted the trends favouring dapagliflozin, with numerically lower rates, and on that basis considered the results to be hypothesis generating [106].

As other endpoints were similar between the two groups, and overall adverse events were fewer with dapagliflozin than placebo, the DARE-19 study was at least able to demonstrate that the use of SGLT2i in patients hospitalized with Covid-19 is well tolerated and does not seem to elevate the risk for poor outcomes [106]. We would find it of interest to see further randomized controlled trials of SGLT2i, as well as GLP-1 RA, perhaps restricted to patients with mild-to-moderate Covid-19, with a view to preventing progression to severe disease or death.

Recommendations for managing glucose-lowering therapy have sought to discriminate between patients at risk of-but not infected with-Covid-19; patients who have mild disease that does not require hospitalization; patients who are hospitalized but not in critical care; and patients who are critically ill [14]-[21]. Based on these criteria, recommendations published to date have tended to agree on favouring insulin in hospitalized patients, where management of hyperglycaemia upon admission is a concern [14]-[21]. However, outside an intensive care setting, safe insulin dosing and glucose monitoring protocols are used inconsistently or not at all, which may result in increased risk of hypoglycaemia [107]. Safer treatments that could be considered include fixed-ratio formulations of GLP-1 RA or SGLT2i with basal insulin [107].

Some recommendations also note that DPP-4i can be considered in addition to insulin in the hospital setting, which may be highly relevant given the overlap in the elderly profile of DPP-4i recipients and patients hospitalized with Covid-19 [23].

Where recommendations disagree is on how to apply sick day rules for SGLT2i and metformin during Covid19 infection, with some advocating for sick day rules with any degree of illness and others reserving this for hospitalized or even critically ill patients [14]-[21]. There is more agreement that no change to normal glucose-lowering treatment is needed in patients who may be at risk of infection but who are not currently infected.

If patients requiring hospitalization for Covid-19 continue on SGLT2i, they should be monitored for DKA, which can occur in patients with Covid-19 independently of treatment, but can sometimes also be associated with SGLT2i use [66]-[68, 108]-[116]. For patients with Covid-19 who are not hospitalized, we suggest that factors that may increase the risk for DKA are considered, namely fluid loss due to diarrhoea or low intake of food and drink due to a suppressed appetite or gastrointestinal symptoms. Patients on metformin with hypoxaemia or organ failure should be monitored for the risk of lactic acidosis, which can occur under these conditions [81].

Due to the paucity of data, all recommendations are based on clinical judgement alone, and made out of necessity without extensive, robust evidence. For this reason, and until such data are available, recommendations should be treated with caution and considered to be heavily caveated.

We are also mindful that the harm of suboptimal management of diabetes should not be overlooked, especially as inadequate glycaemic control has been linked to poor outcomes in patients with Covid-19 [52, 62]-[64]. Similarly, losing the cardiorenal protective effects and weight loss benefits of SGLT2i [117] and GLP-1 RA [22] may be detrimental given the cardiorenal risk posed by both type 2 diabetes and Covid-19, a question that remains open after the inconclusive results of the DARE-19 study [106]. Finally, while data on hypoglycaemia in patients with Covid-19 are limited, this should not deter clinicians from preferring therapies with a low risk of these events.

Taking together our clinical experience and the review of literature discussed here, we suggest that the basic principles of glucose-lowering therapy for patients with type 2 diabetes in a Covid- 19 setting could be directed as outlined in Fig. 2.

\section{After Covid-19: how can we make sure that patients return to optimal control of type 2 diabetes?}

Given that sick day rules and other recommendations may lead to treatment discontinuations in a Covid-19 setting, patients are at risk of losing the benefits of an optimized glucose-lowering drug regimen, especially if there is no systematic process for restarting treatment. 


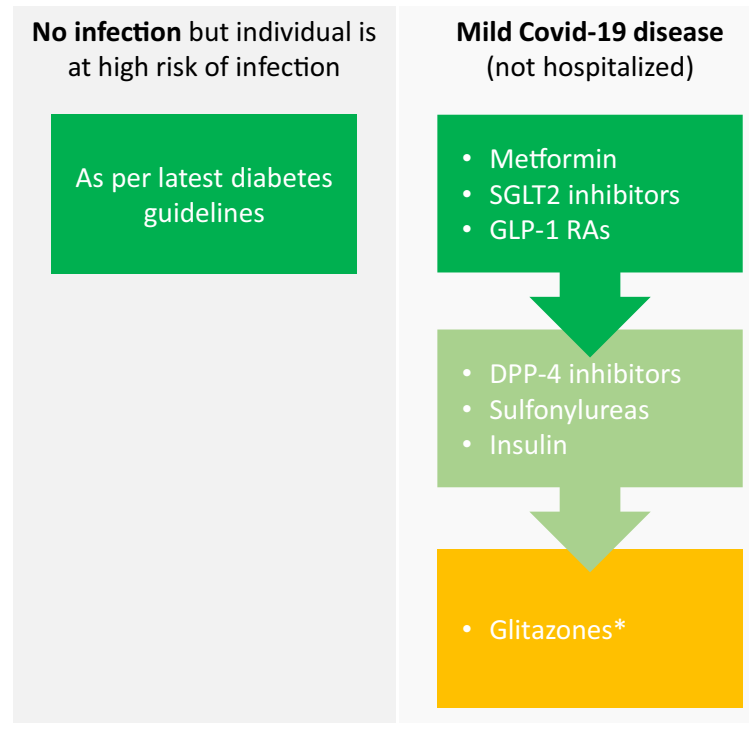

Recommended ( $1^{\text {st }}$ line $)$
Recommended ( $2^{\text {nd }}$ line $)$
Hospitalized with moderate Covid-19 disease

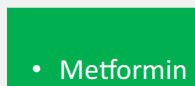

- SGLT2 inhibitors

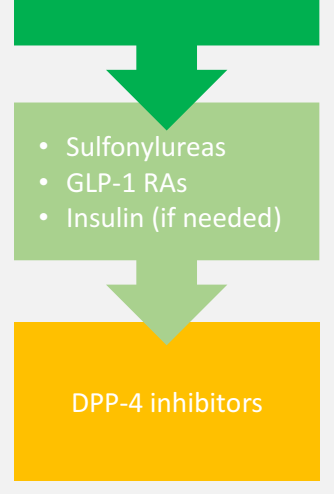

*No longer widely used in some countries

Fig. 2 Suggested principles of glucose-lowering therapy for type 2 diabetes in a Covid-19 setting. In light of the limited available data, including observational studies and the DARE-19 trial, together with diabetes guidelines developed prior to the pandemic, we cautiously suggest these principles of glucose-lowering therapy in a Covid-19 setting. We emphasize that these suggestions are based on our clinical opinion and are not evidence-based, due to the paucity of evidence

However, for patients who had not previously been on a regimen optimized to the latest guidelines, treatment interruption or modification due to Covid-19 could also provide an opportunity to optimize glucose-lowering therapy upon recovery.

For those patients who do need to temporarily change their glucose-lowering regimen, the question remains as to when to de-intensify insulin and optimize treatment following recovery from Covid-19. More guidance is urgently needed to answer this question, but once again we are currently hampered by a lack of evidence.

Unfortunately, it is not straightforward to determine whether a patient has recovered from Covid-19; even once the infection has cleared, other sequalae may remain for some time, and risk of re-admission, MACE and even mortality remain high for a period; [118] it is not known whether this is a consideration for restarting glucoselowering drugs. These difficulties are compounded by the overall strain placed on diabetes and cardiology services during the pandemic $[1,75]$ and the lack of guidance on post-Covid-19 care, with recommendations instead focusing on patients who are infected or at risk of infection [14]-[21]. The lack of guidance is of particular concern when bearing in mind that management of patients who are recovering from Covid-19 may be carried out, in most countries, by non-diabetes specialists.

Unless these challenges are overcome, patients may lose the benefit of their usual treatment regimen, optimized for well-controlled glycaemia and safety considerations; discontinuation may worsen glycaemic control and/or increase the likelihood of adverse effects such as hypoglycaemia. Furthermore, many patients with type 2 diabetes also have co-morbidities that would benefit from the various cardiorenal protective effects offered by agents within the SGLT2i and GLP-1 RA classes. Drug prescription data both prior to $[22,119,120]$ and during [23] the Covid-19 pandemic has shown that many eligible patients do not receive SGLT2i or GLP-1 RA.

While any guidance should be received with caution, given the paucity of data, from our clinical experience and according to our literature review we would suggest that the basic principles of discharge could be directed as follows. Briefly, we advise that de-intensification should be considered at the time of discharge in patients with an intensified insulin regimen, taking into account efficacy, safety, patient burden, patient comfort and patient satisfaction with insulin treatment. The decision should be based on shared, informed decision-making with both the patient and other specialists, especially cardiologists 
and nephrologists, with whom specific comorbidities and special needs should be discussed, such as the benefits of medication offering cardiorenal protection, weight reduction or low risk of hypoglycaemia. The decision could thereby be perceived as an opportunity to improve patient outcomes beyond Covid-19, with optimized antihyperglycaemic treatment as per modern guidelines.

If it is decided that insulin should not be de-intensified at discharge, a timeline of 1 and/or 3 months should be set for re-assessment, which could involve telemedicine options such as online visits, telephone contact or remote access to data from glucose monitoring systems. Frequent monitoring and insulin down-titration are advised if the patient continues with a corticosteroid for Covid19 following discharge from hospital.

\section{Conclusions}

The sudden onset of the Covid-19 pandemic has forced diabetologists to make clinical decisions without the level of evidence that would normally be expected. As time progresses, some studies are beginning to shed light on the potential impact of various glucose-lowering drugs on outcomes such as mortality. However, these are mostly observational studies, while the DARE-19 trial had relatively modest patient numbers and inconclusive results. Notwithstanding these caveats, the emerging evidence suggests that no particular class of glucose-lowering drug carries an elevated risk; outside of an intensive setting, patients may be best served by continuing on their current regimens, with monitoring for DKA or lactic acidosis where appropriate.

While the danger posed by Covid-19 may be receding, the risks of poor glycaemic control and cardiorenal disease remain ever present [22]. Therefore, our hope is that management of type 2 diabetes during the pandemic will lead to new opportunities to optimize treatment to prolong life for patients and improve its quality.

\section{Abbreviations}

AKI: Acute kidney injury; DKA: Diabetic ketoacidosis; DPP-4i: Dipeptidyl peptidase-4 inhibitor; GLP-1 RA: Glucagon-like peptide-1 receptor agonist; HF: Heart failure; MACE: Major adverse cardiovascular event; PCI: Percutaneous coronary intervention; SGLT2i: Sodium-glucose transporter-2 inhibitor; STEMI: ST-segment elevation myocardial infarction; UK: United Kingdom.

\section{Acknowledgements}

Editorial support was provided by Fortis Pharma Consulting, with financial support by Boehringer Ingelheim. The opinions expressed are entirely the authors' own and the only involvement of Boehringer Ingelheim was to have sight of the manuscript for accuracy.

\section{Authors' contributions}

LC and GS chaired the initial discussion meeting, in which all authors participated. All authors contributed to the subsequent development of the manuscript, including both its content and critical review. All authors read and approved the final manuscript.

\section{Funding}

Organisation of an expert discussion meeting that preceded the development of the manuscript was funded and organised by Boehringer Ingelheim, with support from Fortis Pharma Consulting. All editorial and publication costs associated with this article (including editorial support from Fortis Pharma Consulting) were funded by Boehringer Ingelheim.

\section{Availability of data and materials}

All data generated or analysed during this study are included in this published article.

\section{Declarations}

Ethics approval and consent to participate

Not applicable.

\section{Consent for publication}

Not applicable.

\section{Competing interests}

LC has served as a consultant for Abbott, Ascensia, Astra Zeneca, Bayer, Bioton, Boehringer Ingelheim, Eli Lilly, Medicover Foundation, Medtronic, Merck Serono, MSD, Mundipharma, Novo Nordisk, Roche and Sanofi and is on Speakers Bureaus for Abbott, Ascensia, Astra Zeneca, Bayer, Bioton, Boehringer Ingelheim, Eli Lilly, KRKA, Merck Serono, MSD, Novo Nordisk, Sanofi, and Servier, and received research funding from Bioton, Medicover Foundation, and TEVA Pharmaceuticals. DD has received speaker honoraria and consultancy fees from AstraZeneca, Boehringer Ingelheim, Novo Nordisk, Teva, and research grants from Boehringer Ingelheim, Novo Nordisk and Eli Lilly. RL has received honoraria from AstraZeneca, Boehringer Ingelheim, Eli Lilly, Novo Nordisk, Mundipharma, Merck Sharp \& Dohme and Sanofi. MP has received speaker honoraria and has consulted for Abbott, AstraZeneca, Boehringer Ingelheim, Eli Lilly and Company, Merck Sharp \& Dohme, Novartis, Novo Nordisk, Medtronic, Inc., Sanofi, Teva, and Roche. GS has received honoraria from AstraZeneca, Boehringer Ingelheim, Eli Lilly, Mundipharma, Servier and Takeda for speaking at sponsored meetings or attending advisory boards.

\section{Author details}

${ }^{1}$ Department of Diabetology and Internal Medicine, Medical University of Warsaw, Warsaw, Poland. 'Department of Internal Medicine D, Hasharon Hospital, Rabin Medical Centre, Petah Tikva, Israel. ${ }^{3}$ Sackler School of Medicine, Tel Aviv University, Tel Aviv, Israel. ${ }^{4}$ Department of Endocrinology, Diabetes and Nutrition, University Hospital Zürich, Zürich, Switzerland. ${ }^{5} 3$ rd Department of Internal Medicine, 1st Faculty of Medicine, Charles University and General Faculty Hospital, Prague, Czech Republic. ${ }^{6}$ Department of Medicine I, Rudolfstiftung Hospital Vienna, 1030 Vienna, Austria. ${ }^{7}$ Medical University of Vienna, Vienna, Austria.

Received: 4 September 2021 Accepted: 20 September 2021 Published online: 01 October 2021

\section{References}

1. Forde R, et al. The impact of the COVID-19 pandemic on people with diabetes and diabetes services: a pan-European survey of diabetes specialist nurses undertaken by the Foundation of European Nurses in Diabetes survey consortium. Diabet Med. 2021;83:e14498.

2. Mantovani A, Byrne CD, Zheng M-H, Targher G. Diabetes as a risk factor for greater COVID-19 severity and in-hospital death: a meta-analysis of observational studies. Nutr Metab Cardiovasc Dis. 2020;30:1236-48.

3. Corona $\mathrm{G}$, et al. Diabetes is most important cause for mortality in COVID-19 hospitalized patients: systematic review and meta-analysis. Rev Endocr Metab Disord. 2021;22:275-96.

4. de Jong M, Woodward M, Peters SAE. Diabetes and COVID-19-related mortality in women and men in the UK biobank: comparisons with influenza/pneumonia and coronary heart disease. Diabetes Care. 2021:44:e22-4. 
5. Kumar A, et al. Is diabetes mellitus associated with mortality and severity of COVID-19? A meta-analysis. Diabetes Metab Syndr. 2020;14:535-45.

6. Myers AK, et al. Predictors of mortality in a multiracial urban cohort of persons with type 2 diabetes and novel coronavirus 19. J Diabetes. 2021;13:430-8.

7. McGurnaghan SJ, et al. Risks of and risk factors for COVID-19 disease in people with diabetes: a cohort study of the total population of Scotland. Lancet Diabetes Endocrinol. 2021:9:82-93.

8. Sonmez A, et al. Clinical characteristics and outcomes of COVID-19 in patients with type 2 diabetes in Turkey: a nationwide study (TurCoviDia). J Diabetes. 2021;13:585-95.

9. You JH, et al. Clinical outcomes of COVID-19 patients with type 2 diabetes: a population-based study in Korea. Endocrinol Metab. 2020;35:901-8.

10. For the CORONADO investigators, et al. Predictors of hospital discharge and mortality in patients with diabetes and COVID-19: updated results from the nationwide CORONADO study. Diabetologia. 2021;64:778-94.

11. Izzi-Engbeaya C, et al. Adverse outcomes in COVID-19 and diabetes: a retrospective cohort study from three London teaching hospitals. BMJ Open Diabetes Res Care. 2021;9:e001858.

12. Shrestha E, et al. Type 2 diabetes is associated with increased risk of critical respiratory illness in patients COVID-19 in a community hospital. Obes Med. 2021;22:100316.

13. Chung MK, et al. COVID-19 and cardiovascular disease. Circ Res. 2021:128:1214-36.

14. Sun B, Huang $S$, Zhou J. Perspectives of antidiabetic drugs in diabetes with coronavirus infections. Front Pharmacol. 2021;11:592439.

15. Lim S, Bae JH, Kwon H-S, Nauck MA. COVID-19 and diabetes mellitus: from pathophysiology to clinical management. Nat Rev Endocrinol. 2021;17:11-30.

16. Korytkowski $\mathrm{M}$, et al. A pragmatic approach to inpatient diabetes management during the COVID-19 pandemic. J Clin Endocrinol Metab. 2020;105:3076-87.

17. Koliaki C, et al. Clinical management of diabetes mellitus in the era of COVID-19: practical issues, peculiarities and concerns. J Clin Med. 2020;9:2288.

18. Katulanda P, et al. Prevention and management of COVID-19 among patients with diabetes: an appraisal of the literature. Diabetologia. 2020;63:1440-52.

19. Hartmann-Boyce J, et al. Diabetes and COVID-19: risks, management, and learnings from other national disasters. Diabetes Care. 2020;43:1695-703.

20. Futatsugi $\mathrm{H}$, et al. Blood glucose control strategy for type 2 diabetes patients with COVID-19. Front Cardiovasc Med. 2020;7:593061.

21. Bornstein SR, et al. Practical recommendations for the management of diabetes in patients with COVID-19. Lancet Diabetes Endocrinol. 2020;8:546-50.

22. Schernthaner $\mathrm{G}$, et al. Worldwide inertia to the use of cardiorenal protective glucose-lowering drugs (SGLT2i and GLP-1 RA) in high-risk patients with type 2 diabetes. Cardiovasc Diabetol. 2020;19:185.

23. Khunti $K$, et al. Prescription of glucose-lowering therapies and risk of COVID-19 mortality in people with type 2 diabetes: a nationwide observational study in England. Lancet Diabetes Endocrinol. 2021;9:293-303.

24. Drucker DJ. Diabetes, obesity, metabolism, and SARS-CoV-2 infection: the end of the beginning. Cell Metab. 2021;33:479-98.

25. Hui Y, et al. The risk factors for mortality of diabetic patients with severe COVID-19: a retrospective study of 167 severe COVID-19 cases in Wuhan. PLOS ONE. 2020;15:e0243602.

26. Fleming N, Sacks LJ, Pham CT, Neoh SL, Ekinci El. An overview of COVID-19 in people with diabetes: pathophysiology and considerations in the inpatient setting. Diabet Med. 2021;38:e14509.

27. Koh $\mathrm{H}$, et al. Diabetes predicts severity of COVID-19 infection in a retrospective cohort: a mediatory role of the inflammatory biomarker C-reactive protein. J Med Virol. 2021;93:3023-32.

28. Peng $X$, et al. Promising therapy for heart failure in patients with severe COVID-19: calming the cytokine storm. Cardiovasc Drugs Ther. 2021;35:231-47.
29. Pitocco D, et al. Diabetes and severity of COVID-19: what is the link? Med Hypotheses. 2020;143:109923.

30. Zheng $\mathrm{M}$, et al. The cytokine profiles and immune response are increased in COVID-19 patients with type 2 diabetes mellitus. J Diabetes Res. 2021;2021:1-8.

31. Roberts J, et al. Why Is COVID-19 more severe in patients with diabetes? The role of angiotensin-converting enzyme 2, endothelial dysfunction and the immunoinflammatory system. Front Cardiovasc Med. 2021;7:629933.

32. Carrasco-Sánchez FJ, et al. Admission hyperglycaemia as a predictor of mortality in patients hospitalized with COVID-19 regardless of diabetes status: data from the Spanish SEMI-COVID-19 Registry. Ann Med. 2021:53:103-16.

33. Holman N, et al. Risk factors for COVID-19-related mortality in people with type 1 and type 2 diabetes in England: a population-based cohort study. Lancet Diabetes Endocrinol. 2020;8:823-33.

34. Abdelhafiz A, Emmerton D, Sinclair A. Diabetes in COVID-19 pandemicprevalence, patient characteristics and adverse outcomes. Int I Clin Pract. 2021. https://doi.org/10.1111/ijcp.14112.

35. Apicella M, et al. COVID-19 in people with diabetes: understanding the reasons for worse outcomes. Lancet Diabetes Endocrinol. 2020;8:782-92.

36. Corcillo A, Whyte MB, Vas P, Karalliedde J. Microvascular disease in diabetes and severe COVID-19 outcomes. Lancet Diabetes Endocrinol. 2021;9:200-1.

37. Petrilli $\mathrm{CM}$, et al. Factors associated with hospital admission and critical illness among 5279 people with coronavirus disease 2019 in New York City: prospective cohort study. BMJ. 2020;369:m1966.

38. Palaiodimos $\mathrm{L}$, et al. Severe obesity, increasing age and male sex are independently associated with worse in-hospital outcomes, and higher in-hospital mortality, in a cohort of patients with COVID-19 in the Bronx, New York. Metabolism. 2020;108:154262.

39. Scheen AJ. SGLT2 inhibition during the COVID-19 epidemic: friend or foe? Diabetes Metab. 2020;46:343-4.

40. Shah H, Khan MSH, Dhurandhar NV, Hegde V. The triumvirate: why hypertension, obesity, and diabetes are risk factors for adverse effects in patients with COVID-19. Acta Diabetol. 2021;58:831-43.

41. Shi Q, et al. Clinical characteristics and risk factors for mortality of COVID-19 patients with diabetes in Wuhan, China: a two-center retrospective study. Diabetes Care. 2020;43:1382-91.

42. Sourij H, et al. COVID-19 fatality prediction in people with diabetes and prediabetes using a simple score upon hospital admission. Diabetes Obes Metab. 2021;23:589-98.

43. Lasbleiz A, et al. Phenotypic characteristics and development of a hospitalization prediction risk score for outpatients with diabetes and COVID-19: the DIABCOVID study. J Clin Med. 2020;9:3726.

44. Abe T, et al. Cardiovascular complications in COVID-19 patients with or without diabetes mellitus. Endocrinol Diabetes Metab. 2021;4:e00218.

45. Lax SF, et al. Pulmonary arterial thrombosis in COVID-19 with fatal outcome : results from a prospective, single-center clinicopathologic case series. Ann Intern Med. 2020;173:350-61.

46. Iba T, Connors JM, Nagaoka I, Levy JH. Recent advances in the research and management of sepsis-associated DIC. Int J Hematol. 2021;113:24-33.

47. Shen Y, et al. Thresholds of glycemia and the outcomes of COVID-19 complicated with diabetes: a retrospective exploratory study using continuous glucose monitoring. Diabetes Care. 2021;44:976-82.

48. Kapoor $\mathrm{R}$, et al. Maintaining blood glucose levels in range ( $70-150 \mathrm{mg} /$ $\mathrm{dL}$ ) is difficult in COVID-19 compared to non-COVID-19 ICU patients-a retrospective analysis. J Clin Med. 2020;9:3635.

49. Pettrone $K$, et al. Characteristics and risk factors of hospitalized and nonhospitalized COVID-19 patients, Atlanta, Georgia, USA, March-April 2020. Emerg Infect Dis. 2021;27:1164-8.

50. Smati $S$, et al. Relationship between obesity and severe COVID -19 outcomes in patients with type 2 diabetes: results from the CORONADO study. Diabetes Obes Metab. 2021;23:391-403.

51. Sutter W, et al. Association of diabetes and outcomes in patients with COVID-19: propensity score-matched analyses from a French retrospective cohort. Diabetes Metab. 2021;47:101222.

52. Gao F, et al. Obesity is a risk factor for greater COVID-19 severity. Diabetes Care. 2020;43:e72-4. 
53. Gao C, et al. Association of hypertension and antihypertensive treatment with COVID-19 mortality: a retrospective observational study. Eur Heart J. 2020;41:2058-66.

54. Bikdeli B, et al. COVID-19 and thrombotic or thromboembolic disease: implications for prevention, antithrombotic therapy, and follow-up. J Am Coll Cardiol. 2020;75:2950-73.

55. Helms J, et al. High risk of thrombosis in patients with severe SARSCoV-2 infection: a multicenter prospective cohort study. Intensiv Care Med. 2020;46:1089-98.

56. Harrison SL, Fazio-Eynullayeva E, Lane DA, Underhill P, Lip GYH. Higher mortality of ischaemic stroke patients hospitalized with COVID-19 compared to historical controls. Cerebrovasc Dis. 2021;50:326-31.

57. Chioh FW, et al. Convalescent COVID-19 patients are susceptible to endothelial dysfunction due to persistent immune activation. Elife. 2021;10:e64909.

58. Holland D, et al. Impact of the UK COVID-19 pandemic on HbA1c testing and its implications for diabetes diagnosis and management. Int J Clin Pract. 2021;75:e13980.

59. Moreno R, et al. Impact of diabetes in patients waiting for invasive cardiac procedures during COVID-19 pandemic. Cardiovasc Diabetol. 2021;20:69.

60. Jacob L, Rickwood S, Rathmann W, Kostev K. Change in glucose-lowering medication regimens in individuals with type 2 diabetes mellitus during the COVID-19 pandemic in Germany. Diabetes Obes Metab. 2021;23:910-5.

61. Ledford CJW, et al. Quantifying worsened glycemic control during the COVID-19 pandemic. J Am Board Fam Med. 2021;34:S192-5.

62. Klonoff DC, et al. Association between achieving inpatient glycemic control and clinical outcomes in hospitalized patients with COVID-19: a multicenter retrospective hospital-based analysis. Diabetes Care. 2021:44:578-85.

63. Sardu C, et al. Outcomes in patients with hyperglycemia affected by COVID-19: can we do more on glycemic control? Diabetes Care. 2020;43:1408-15.

64. Shen $Y$, Zhang L, Fan X, Zhou J. Glycemic fluctuations caused by COVID-19: Results from continuous glucose monitoring. Obes Med. 2021:22:100328.

65. Chen $L$, et al. Association of early-phase in-hospital glycemic fluctuation with mortality in adult patients with Coronavirus disease 2019. Diabetes Care. 2021;44:865-73.

66. Accili D. Can COVID-19 cause diabetes? Nat Metab. 2021;3:123-5.

67. Misra S, et al. Comparison of diabetic ketoacidosis in adults during the SARS-CoV-2 outbreak and over the same time period for the preceding 3 years. Diabetes Care. 2021;44:e29-31.

68. Kempegowda P, et al. Effect of COVID-19 on the clinical course of diabetic ketoacidosis (DKA) in people with type 1 and type 2 diabetes. Endocr Connect. 2021:10:371-7.

69. Braithwaite SS, Bavda DB, Idrees T, Qureshi F, Soetan OT. Hypoglycemia reduction strategies in the ICU. Curr Diabetes Rep. 2017;17:133.

70. Bhatt AS, et al. Fewer hospitalizations for acute cardiovascular conditions during the COVID-19 pandemic. J Am Coll Cardiol. 2020;76:280-8.

71. De Filippo O, et al. Reduced rate of hospital admissions for ACS during Covid-19 outbreak in Northern Italy. N Engl J Med. 2020;383:88-9.

72. De Rosa $\mathrm{S}$, et al. Reduction of hospitalizations for myocardial infarction in Italy in the COVID-19 era. Eur Heart J. 2020:41:2083-8.

73. De Luca G, et al. Impact of COVID-19 pandemic and diabetes on mechanical reperfusion in patients with STEMI: insights from the ISACS STEMI COVID 19 Registry. Cardiovasc Diabetol. 2020;19:215.

74. D’Amario D, Rodolico D, Cappannoli L, Migliaro S, Crea F. Are we missing something in the management of acute coronary syndromes in COVID19-negative patients? J Am Coll Cardiol. 2020;76:2573-4.

75. Einstein AJ, et al. International impact of COVID-19 on the diagnosis of heart disease. J Am Coll Cardiol. 2021;77:173-85.

76. Banerjee $A$, et al. Excess deaths in people with cardiovascular diseases during the COVID-19 pandemic. Eur J Prev Cardiol. 2021. https://doi. org/10.1093/eurjpc/zwaa155.

77. Singh AK, Singh R, Saboo B, Misra A. Non-insulin anti-diabetic agents in patients with type 2 diabetes and COVID-19: a critical appraisal of literature. Diabetes Metab Syndr. 2021;15:159-67.

78. Schofield J, Leelarathna L, Thabit H. COVID-19: impact of and on diabetes. Diabetes Ther. 2020;11:1429-35.
79. Bramante CT, et al. Metformin and risk of mortality in patients hospitalised with COVID-19: a retrospective cohort analysis. Lancet Healthy Longev. 2021;2:e34-41.

80. Crouse $A B$, et al. Metformin use is associated with reduced mortality in a diverse population with COVID-19 and diabetes. Front Endocrinol. 2021;11:600439.

81. Dardano A, Del Prato S. Metformin: an inexpensive and effective treatment in people with diabetes and COVID-19? Lancet Healthy Longev. 2021;2:e6-7.

82. Lalau J-D, et al. Metformin use is associated with a reduced risk of mortality in patients with diabetes hospitalised for COVID-19. Diabetes Metab. 2021:47:101216

83. Pal R, et al. Dipeptidyl peptidase-4 inhibitor use and mortality in COVID19 patients with diabetes mellitus: an updated systematic review and meta-analysis. Ther Adv Endocrinol Metab. 2021;12:2042018821996482.

84. Ursini F, Ciaffi J, Landini MP, Meliconi R. COVID-19 and diabetes: is metformin a friend or foe? Diabetes Res Clin Pract. 2020;164:108167.

85. Wang J, et al. Association of metformin with susceptibility to COVID-19 in people with Type 2 diabetes. J Clin Endocrinol Metab. 2021;106:1255-68.

86. Lui DTW, Tan KCB. Is metformin a miracle or a menace in COVID-19 patients with type 2 diabetes? J Diabetes Investig. 2021;12:479-81.

87. Lally MA, et al. Metformin is associated with decreased 30-day mortality among nursing home residents infected with SARS-CoV2. J Am Med Dir Assoc. 2021:22:193-8.

88. Kahkoska AR, et al. Association between glucagon-like peptide 1 receptor agonist and sodium-glucose Cotransporter 2 inhibitor use and COVID-19 outcomes. Diabetes Care. 2021;44:1564-72.

89. Bonora BM, Avogaro A, Fadini GP. Disentangling conflicting evidence on DPP-4 inhibitors and outcomes of COVID-19: narrative review and meta-analysis. J Endocrinol Invest. 2021:44:1379-86.

90. Fadini GP, et al. Exposure to dipeptidyl-peptidase-4 inhibitors and COVID -19 among people with type 2 diabetes: a case-control study. Diabetes Obes Metab. 2020;22:1946-50.

91. lacobellis G. COVID-19 and diabetes: Can DPP4 inhibition play a role? Diabetes Res Clin Pract. 2020;162:108125.

92. Kow CS, Hasan SS. Use of DPP-4 inhibitors in patients with COVID-19. Acta Diabetol. 2021;58:245-6.

93. Nauck MA, Meier JJ. Reduced COVID-19 mortality with sitagliptin treatment? Weighing the dissemination of potentially lifesaving findings against the assurance of high scientific standards. Diabetes Care. 2020:43:2906-9.

94. Noh Y, et al. Association between DPP-4 inhibitors and COVID-19 related outcomes among patients with type 2 diabetes. Diabetes Care. 2021;44:e64-6.

95. Israelsen SB, et al. Comparable COVID-19 outcomes with current use of GLP-1 receptor agonists, DPP-4 inhibitors or SGLT-2 inhibitors among patients with diabetes who tested positive for SARS-CoV-2. Diabetes Obes Metab. 2021;23:1397-401.

96. Roussel $\mathrm{R}$, et al. Use of dipeptidyl peptidase-4 inhibitors and prognosis of COVID -19 in hospitalized patients with type 2 diabetes: a propensity score analysis from the CORONADO study. Diabetes Obes Metab. 2021:23:1162-72.

97. Scheen AJ. DPP-4 inhibition and COVID-19: From initial concerns to recent expectations. Diabetes Metab. 2021;47:101213.

98. Solerte SB, et al. Sitagliptin treatment at the time of hospitalization was associated with reduced mortality in patients with type 2 diabetes and COVID-19: a multicenter, case-control, retrospective observational study. Diabetes Care. 2020;43:2999-3006.

99. Valencia I, et al. DPP4 and ACE2 in diabetes and COVID-19: therapeutic targets for cardiovascular complications? Front Pharmacol. 2020;11:1161.

100. Ramos-Rincón JM, et al. Cardiometabolic Therapy and mortality in very old patients with diabetes hospitalized due to COVID-19. J Gerontol Ser A. 2021;76:e102-9.

101. Schernthaner G. Effects of a DPP-4 inhibitor and RAS blockade on clinical outcomes of patients with diabetes and COVID-19 (Diabetes Metab J 2021;45:251-9). Diabetes Metab J. 2021;45:615-6.

102. Donath MY. Glucose or insulin, which is the culprit in patients with COVID-19 and diabetes? Cell Metab. 2021:33:2-4 
103. Falcetta P, et al. Impact of COVID-19 lockdown on glucose control of elderly people with type 2 diabetes in Italy. Diabetes Res Clin Pract. 2021;174:108750.

104. Yu B, Li C, Sun Y, Wang DW. Insulin treatment is associated with increased mortality in patients with COVID-19 and type 2 diabetes. Cell Metab. 2021;33:65-77.e2.

105. Schernthaner G. Can glucose-lowering drugs affect the prognosis of COVID-19 in patients with type 2 diabetes? Lancet Diabetes Endocrinol. 2021:9:251-2.

106. Kosiborod MN, et al. Dapagliflozin in patients with cardiometabolic risk factors hospitalised with COVID-19 (DARE-19): a randomised, doubleblind, placebo-controlled, phase 3 trial. Lancet Diabetes Endocrinol. 2021;9:586-94.

107. Giugliano $D$, et al. Feasibility of simplification from a basal-bolus insulin regimen to a fixed-ratio formulation of basal insulin plus a GLP-1RA or to basal insulin plus an SGLT2 inhibitor: BEYOND, a randomized pragmatic trial. Diabetes Care. 2021;44:1353-60.

108. Batista DV, de Almeida Vieira CAF, Costa TA, Lima EG. COVID-19-associated euglycemic diabetic ketoacidosis in a patient with type 2 diabetes on SGLT2 inhibitor: a case report. Diabetol Int. 2021:12:313-6.

109. Dass B, Beck A, Holmes C, Morton G. Euglycemic DKA (euDKA) as a presentation of COVID-19. Clin Case Rep. 2021;9:395-8.

110. Fang J, Genco M, Caskey RN. COVID-19 precipitating euglycaemic diabetic ketoacidosis with SGLT2 inhibitor use. Eur J Case Rep Intern Med. 2020;7:001943.

111. Gorthi RS, Kamel G, Dhindsa S, Nayak RP. COVID-19 presenting with diabetic ketoacidosis: a case series. AACE Clin Case Rep. 2021;7:6-9.

112. Morrison N, Barnett K, Tantum J, Morrison HK, Whalen M. A case of euglycemic diabetic ketoacidosis in a patient with type 2 diabetes mellitus and COVID-19. Cureus. 2020;12:e12029.

113. Ozer O, Yorulmaz G. Euglycemic diabetic ketoacidosis associated with empagliflozin use in the course of the SARS-Cov-2 pandemic. J Coll Physicians Surg Pak. 2020;30:110-1.

114. Pasquel FJ, et al. Characteristics of and mortality associated with diabetic ketoacidosis among US patients hospitalized with or without COVID-19. JAMA Netw Open. 2021;4:e211091.
115. Vitale RJ, Valtis YK, McDonnell ME, Palermo NE, Fisher NDL. Euglycemic diabetic ketoacidosis with COVID-19 infection in patients with type 2 diabetes taking SGLT2 inhibitors. AACE Clin Case Rep. 2021;7:10-3.

116. Xu C, Zia U. Recovery from acute kidney injury with diabetic ketoacidosis following SARS-CoV-2 infection: a case report and literature review. Cureus. 2020;12:e11702.

117. Kosiborod $\mathrm{M}$, et al. Effects of dapagliflozin on prevention of major clinical events and recovery in patients with respiratory failure because of COVID-19: design and rationale for the DARE-19 study. Diabetes Obes Metab. 2021;23:886-96.

118. Ayoubkhani $\mathrm{D}$, et al. Post-covid syndrome in individuals admitted to hospital with covid-19: retrospective cohort study. BMJ. 2021;372:n693.

119. Pintaudi $B$, et al. Clinical profiles and quality of care of subjects with type 2 diabetes according to their cardiovascular risk: an observational, retrospective study. Cardiovasc Diabetol. 2021;20:59.

120. Nargesi AA, et al. Contemporary national patterns of eligibility and use of novel cardioprotective antihyperglycemic agents in type 2 diabetes mellitus. J Am Heart Assoc. 2021;10:e021084.

121. For the SEMI-COVID-19 Network, et al. Mortality and other adverse outcomes in patients with type 2 diabetes mellitus admitted for COVID-19 in association with glucose-lowering drugs: a nationwide cohort study. BMC Med. 2020;18:359.

122. Sainsbury C, et al. Sodium-glucose co-transporter- 2 inhibitors and susceptibility to COVID-19: a population-based retrospective cohort study. Diabetes Obes Metab. 2021;23:263-9.

123. Kow CS, Hasan SS. Mortality risk with preadmission metformin use in patients with COVID-19 and diabetes: a meta-analysis. J Med Virol. 2021;93:695-7.

\section{Publisher's Note}

Springer Nature remains neutral with regard to jurisdictional claims in published maps and institutional affiliations.
Ready to submit your research? Choose BMC and benefit from:

- fast, convenient online submission

- thorough peer review by experienced researchers in your field

- rapid publication on acceptance

- support for research data, including large and complex data types

- gold Open Access which fosters wider collaboration and increased citations

- maximum visibility for your research: over 100M website views per year

At BMC, research is always in progress.

Learn more biomedcentral.com/submissions 